\title{
The Tao of Quantum Management
}

Zhang Ruimin has made clear that, when drafting the RenDanHeyi business model, his thinking was inspired both by his life-long interest in Taoism as a model for leadership, and by quantum physics as articulated through my own work on Quantum Management Theory. One of my arguments in this book is that the wider adoption of quantum thinking, and of RenDanHeyi as a business, social, and political model would provide an important bridge between East and West. For all practical purposes, I believe that the Western science of quantum physics is simply the Eastern philosophy of Taoism expressed in equations and verified by experiment. The implications of each for the nature of reality and for the way that we humans can best conduct our affairs, and thus for leadership and organizational thinking, are largely the same.

Understanding the striking similarities and worldviews of Taoism and quantum physics, and the way they have been integrated and implemented through RenDanHeyi may help both East and West understand how they can learn from each other and perhaps work more harmoniously together in building a new world order. Much of the current, mutual misunderstanding and suspicion felt by both China and the West stems from the fact that the entire thinking structure of the two cultures is radically different, and each sees the other through the lens of its own thinking. Now that life, business, and global relations in the twentyfirst century require a quantum world view held by all, there may be a convergence of understanding and collaboration.

D. Zohar, Zero Distance, https://doi.org/10.1007/978-981-16-7849-3_6 
Western scientists discovered quantum physics, but they have never understood it. Einstein called it "schizophrenic physics" and "Alice-inWonderland physics," others called it "absurd." But the Chinese have understood the quantum vision of reality for over 3000 years. It is embedded in ancient Chinese philosophy, particularly Taoism and then in the Taoist influence on Neo-Confucian philosophy centuries later. And still today, the Chinese people naturally think in a quantum way. Even the Chinese language, Mandarin, with its emphasis on patterns and relationships and its comfort with paradox and ambiguity, invites its users to "think quantum."

Perhaps the most challenging feature of both quantum physics and Chinese thinking for Western people to understand is their understanding of polarity and duality, such as particle/wave or matter/energy duality in quantum physics - which mirror the $l i / q i$ duality in Chinese philosophy. In Chinese thinking, everything in the universe, including ideas, is structured in pairs of polar opposites, like yin/yang, but for the Chinese these are complementary opposites that, like the two sides of a coin, could not exist without each other. Each is essential to an understanding of a thing or an idea, and it is from out of their co-creative dialogue that existence or meaning emerges. Yang, the strong, or light force, could not exist or function without yin, the receptive, or dark force, and the creative relationship between the two. Similarly, $l i$, the structuring principles of the universe, would have no purpose without $q i$, the energy, or creative force and its potentiality, that gets structured. Similarly, in quantum physics, particles could not exist without waves, nor actuality without potentiality. Both are co-present and co-active in any thing or event.

Thus the I Ching, or Chinese Book of Changes, which offers commentary on sixty-four hexagram patterns, actually consists of thirty-two pairs of complementary opposites, and to fully understand the "image" or "judgement" of any one hexagram, the reader must refer to those of its two, component and complementary trigrams. The I Ching was actually the inspirational model for Niels Bohr's famous "Principle of Complementarity." Struggling to understand wave/particle duality from any Western perspective, Bohr, a Danish physicist and one of the five founding fathers of quantum physics, turned to his familiarity with the I Ching for a model that could mirror this "weird" reality. Similarly, two other quantum physics' founders, Wolfgang Pauli and Erwin Schrodinger (of 
"Schrodinger's Cat" fame), turned to their knowledge of Chinese philosophy in an attempt to understand their own new discoveries. Schrodinger actually became a Buddhist.

This need to attempt an understanding of quantum physics in terms of Chinese thought was necessitated because, in Western thought, polarities like strong and weak, or light and darkness, are conflicting opposites. Strong is the opposite of weak, light the opposite of darkness. Similarly, in Western management thinking, management and labor, or the leader and employees, are seen as essentially different and very often in conflict, just as in Western societies, the interests and identity of "I" or "We" are seen as often in conflict with "others," or "them." It is essential for any proper understanding of Quantum Management, or its implementation through the RenDanHeyi, that readers think of such polarities in Chinese, rather than Western, terms. I think it no accident that it was a Chinese CEO who conceived and implemented the RenDanHeyi management model, and quite natural that China's prime minister would recommend this as the ideal business model for all Chinese companies to adopt. Indeed, Quantum Management has now become so widespread in China that the Chinese are calling it "Chinese Management."

Because all of twenty-first-century technology is quantum technology, this indigenous quantum thinking is giving the Chinese a natural competitive edge. Consider Huawei's advanced 5G telecommunications system, the fact that the Chinese have launched the world's first quantum satellite, and the very advanced work that Chinese scientists are doing to develop quantum computers. I will point out in later chapters that we can see echoes of RenDanHeyi in China's bold, international Belt and Road infrastructure project, and even in an ideally practiced model of the way the modern Chinese government structures the organization of its state. Let us look at the philosophical and cultural roots of this.

During the past 3000 years, Chinese civilization has evolved in dialogue with three great philosophies: Taoism, Confucianism, and Ch'an (Zen) Buddhism. Being the oldest of the three, there are shades of Taoist thinking in each of the other two, and then in the tenth to sixteenth centuries, the defining elements of all three were integrated in an emerging and unifying Neo-Confucian philosophy. The greatest of the Taoist thinkers was Lao Tzu, whose Tao Te Ching is one of China's most formative books, and also a book now familiar to many in the West. Lao Tzu described the nature of the universe, the place of human beings within it, and the natural Way for human beings and their leaders to 
live in harmonious alignment with both "Heaven" and each other. The greatest of the Neo-Confucian philosophers was the sixteenth-century Wang Yangming, who adhered to basic Taoist ideas but elaborated much more on the nature and natural inclinations of the self, the source and nature of morality, the relationship and duties of individuals to society, and the principles of harmonious governance. I have found Wang Yangming's philosophy very close to the quantum philosophy I have spent my own life trying to articulate.

\section{Taoist Principles and Quantum Management}

- Made of Energy, Governed by Principles: Newton's static and predictable, materialist universe is made of separate, isolated atoms that are impenetrable and unchanging. Designed and structured as a machine is designed and structured, as a collection of separate, moving parts, this universe is controlled from above by the iron laws of physics, Newton's three Laws of Motion. The Laws of Motion themselves were decreed by a God who is outside the system and wholly other than anything inside it. This view of the universe gave rise in Western culture to a view of society consisting of atomistic individuals with no intimate relationship to each other and only a transactional relationship to society, mediated by laws and social norms. In the Taylorian company, it gave rise to companies modeled as machines, structured into atomistic, siloed divisions and functions, and ruled from above by the dictates of a CEO who, like the Western God, is wholly other than and outside the system. The atomistic employees of the Taylorian company have no direct relationship to each other and only a transactional relationship to the company, mediated by the CEO's rules, their assigned roles in the company structure, and their dependence on the company for a salary.

Taoist philosophy, by contrast, like quantum physics, portrays a dynamic and evolving universe made of energy (qi) and impregnated with a network of self-organizing and harmonius, symbiotically related patterns $(l i)$, or principles, that then give a sense of direction to the self-organizing creation and behavior of all things. These patterns, like the laws of quantum physics, emerged from within the system itself, and define a 
sense of direction, or Way, for the evolving universe to unfold. It is important to stress they are principles, not rules. All things, including ourselves, are guided by these principles, but not controlled by them.

The principles of the Way are a pattern which can be expressed in many different ways, not a structure in the Newtonian sense, which limits expression or action to just one, limited direction. In Quantum Management, this same idea is implemented by the central operational system of the RenDanHeyi model, that gives a company its sense of a common direction and culture, and each self-organizing team or microenterprise targets to aim for, while at the same time allowing them the freedom to work out their own best way of doing so in direct dialogue with their customers/users and the entire ecosystem environment. And, true to both the Taoist and quantum insights that everything is energy, the RenDanHeyi model treats a. company as an energy system. Zhang Ruimin even refers to Haier's microenterprises as "energy balls."

- No Force; "Non-Action": We have seen that Newton's physics portrays a universe designed at the top and tightly controlled by forces and his three Laws of Motion. Thus the Taylorian company is governed by rules imposed from the top, and force (sanctions, punishments) is used to ensure these rules are obeyed. But both Taoism and quantum physics warn of the destructive effects of any force or control imposed on a system from the outside. The very essence of Taoism is its principle of "non-action" ( wu wei), the insight that the greatest effectiveness is achieved when one "goes with the flow," harmoniously aligning oneself and one's actions with the natural Way (Tao) of events rather than forcing one's will upon them. Lao Tzu writes,

Even the best will in the world, when forced, achieves nothing.

The best righteousness, when forced, achieves nothing.

The best good-form when forced does not come out right. ${ }^{1}$

And we know that in quantum physics, any outside interference with or measurement of a quantum system "collapses the wave function,"

${ }^{1}$ Tao te Ching, No. 38. 
robbing the system of its multiple possibilities, just as outside control imposed on a complex adaptive system (living quantum system), interferes with the internal self-organization and robs the system of its creativity. Thus Quantum Management teaches that the CEO must give up control, and power should be distributed to self-organizing teams throughout the company system. The RenDanHeyi business model implements this by giving powers of decision-making, hiring, and remuneration to the independent microenterprise teams, and has them working directly with customers/users and with each other. The quantum leader governs with a light touch as though heeding Lao Tzu's advice to, "Govern a large [company] as you would cook a small fish: lightly.”

- Everything is Connected to Everything: We have seen that Newton's universe is composed of separate, isolated atoms that cannot get inside each other and can relate across the distance that separates them only by the imposition of some force. And thus the Taylorian company is composed of separate functions and separate siloed departments, management is separate from (above) employees, and employees are separate from customers. By contrast, both Taoism and quantum physics tell us that "separation is an illusion," that we live in a world of Zero Distance where everything and everyone is entangled with everything and everyone else.

One Taoist master compared the universe to a multidimensional network of jewels, each jewel containing the reflections of all the others, and said there is no obstruction or distance between one "thing-event" and another. Lao Tzu taught that the whole universe is within each thing or person in it, and each thing or person is within every other. In quantum physics, the entangled wave patterns of every quantum entity ensure this same thing, and thus apparently distant particles are in fact connected nonlocally. The quantum universe is like a large hologram, in which the entire hologram is implicit in each small section of it. So as in Taoism, quantum physics also tells us the entire universe is within each atom or thing. And the RenDanHeyi Quantum Management model, also called the Zero Distance Model, sees every microenterprise in the company in a cocreative relationship with every other, with its customers/users, and with other companies in the ecosystem. Thus the whole company is in every part, and every part is implicit within every other. There are no borders. 
- A Participatory Universe: Just as Western culture and Western grammar distinguish between the subject and the object, Newtonian science distinguishes between the observer and the observed, and the Taylorian company, often seeing itself as an island, distinguishes between what is "inside" the company, and what is "outside." In Newton's materialistic universe, there is no place or role for conscious beings like ourselves. We can only stand back from afar as outsiders and view reality, often as its pawns or victims. But just as quantum physics tells us that the observer and the observed are one, that the way we observe, question, or act within reality co-creates that reality. So, too, Taoism tells us that the Tao is within each of us and each of us is within the Tao, and that it is our acting in alignment with the Tao that can influence the course of the Tao itself. Both the Taoist and the quantum person are agents of cosmic possibility, makers of reality. And because they make the world, they are responsible for the world. The story of the universe is our story, and our story is the story of the universe.

Quantum Management argues that the company is inside the community and the world, and the community and the world are inside the company. Together they make the world and thus, through their relationship, they are responsible for the world. We have seen that in the way that Haier itself implements the RenDanHeyi model, not only is each microenterprise inside every other, but both the customer/user and the community are literally inside the company, sometimes indistinguishable from employees, and the company is inside them (their lifestyles, health care, etc.). It is these cocreative relationships that are constantly giving birth to new, emergent realities-new products and new opportunities for growth.

- Always in Context. In Newton's physics, a thing just is what it is, no matter what its surroundings or relationships, and we have seen that Taylorian companies behave as though they are islands onto themselves, oblivious to the world around them and thus often damaging both their own bottom line and the surrounding environment. Indeed, Western thinking in general tends to solve problems by isolating them as best possible. "Just forget about everything else and concentrate on what is important here," or the admonition, "Get to the point!" 
In Taoist thought, which insists everything is in relationship with everything, and it is understood relationships make reality, the larger surroundings of a word, an action, or an event are seen as shaping them. Thus Chinese thought is always "situational" or "contextual." You can never know the meaning of a Chinese pictogram except through its relation to others in a sentence, never understand an action or an event unless you know "the whole story," and never make a decision without exploring all the factors bearing on it and all those it might bear upon. I can't count the number of times I have stood for more than half an hour on a Beijing street corner with a group of Chinese friends while they consider every possible factor influencing their decision before they hail down a taxi cab to take us to a restaurant. Once seated in the restaurant, they seem to avoid any further long-winded decisions by simply ordering everything on the menu!

And we have seen that "contextuality" is one of the defining principles of quantum physics. A quantum entity or quantum system always is what it is depending upon its context, upon what it is in relationship to. Change the relationship, you change the entity. Quantum Management thus always calls upon a company to consider all its relationships, both internal and external, because these will affect the outcome of strategies and decisions and indeed the very health of the company. Business, and any business decision, always happens within a context. In the RenDanHeyi model, this awareness of context and its power accounts for the "no borders" slogan and a company culture that stresses relationships and understands how all internal and external factors shape the company and its health. And its reliance on a network of interconnected but at the same time independent microenterprises, each operating in a different context, allows a company implementing it to spread both risk and opportunity.

- Spontaneity. Everything in Newtonian physics and the modern Western mindset that arose in response to it fights the very idea of spontaneity. The promise of Newton's physics was that, if we know the starting position of a particle or situation, and we know the forces acting upon them, we can know everything, predict everything, and control everything. Forced control is thus in the Western DNA, and of course it reigns supreme in the Taylorian company, with its reliance on top-down control and rigid bureaucratic structure. In times of uncertainty and rapid, unpredictable, disruptive change, these companies find themselves like heavy, lumbering dinosaurs trying to navigate themselves through a delicate and shifting terrain. 
But both Taoism and quantum physics have always known that complete knowledge is unobtainable, prediction unreliable and often impossible, and control destructive.

Taoism has always taught that the Tao itself, the Way that universe unfolds as it evolves, is always changing, and the only successful way to thrive in this world is to remain spontaneous and rule with a light touch, creatively responding to the flow of unpredictable events rather than by reacting to them with forced control. "The Tao in Nature does not contend, yet skillfully triumphs. Does not speak, yet skillfully responds. Does not summon, and yet attracts. Does not hasten, yet skillfully designs." 2 The Taoist leader triumphs "by accepting, incorporating, and supporting change. Our cooperation with the forces in Nature makes us a part of those forces. Our decisions become astute because they are based on a dynamic, evolving reality, not on fixed or wishful thinking." 3

Quantum physics and complexity science, too, describe an indeterminate, ever-changing and self-organizing Nature, and counsel spontaneous adaptation to the evolving flow of events rather than any attempt to forcefully control them. Quantum Management calls upon the leader to surrender control and to lead with attitude, character, and example rather than forcing his/her will upon the organization as it spontaneously responds to surrounding challenges. The RenDanHeyi management model builds an "autopoetic" organization that can continuously selfgenerate and spontaneously adapt and evolve to ever-changing external circumstances. A quantum company is light, guided by patterns and principles that allow it to surface freely on the currents of market-influencing events as a butterfly does on the currents of the wind.

Thus we can see that China's 3000 years of thinking and culture, originating in and always incorporating Taoist principles, has well prepared modern China to thrive in the Quantum Age. Chinese scientists have an edge with innovative quantum technology because they have a natural, intuitive feel for the laws and principles underlying its development and use. And Chinese business leaders have that same natural, intuitive feel for how quantum organizations work. At the same time, the Western world is now handicapped with a mindset geared to simple, predictable, controllable, and atomistic/mechanistic systems in an age defined by complexity,

2 Tao te Ching, No. 73.

3 A.L. Wing, The Tao of Power, p. 12. 
unpredictable, rapid change, and global interconnectivity and in which control is self-defeating. I am not expecting the Western world suddenly to become Chinese, but if we do not become quantum, we are destined to further decline and perhaps oblivion. We in the West discovered quantum physics. It is imperative we now develop a quantum mindset that can understand it, can live it, and thus find our own way to thrive on the challenges and opportunities it presents. The rest of this book is a guide for doing that.

Open Access This chapter is licensed under the terms of the Creative Commons Attribution-NonCommercial-NoDerivatives 4.0 International License (http:// creativecommons.org/licenses/by-nc-nd/4.0/), which permits any noncommercial use, sharing, distribution and reproduction in any medium or format, as long as you give appropriate credit to the original author(s) and the source, provide a link to the Creative Commons license and indicate if you modified the licensed material. You do not have permission under this license to share adapted material derived from this chapter or parts of it.

The images or other third party material in this chapter are included in the chapter's Creative Commons license, unless indicated otherwise in a credit line to the material. If material is not included in the chapter's Creative Commons license and your intended use is not permitted by statutory regulation or exceeds the permitted use, you will need to obtain permission directly from the copyright holder.

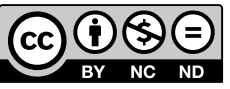

